\title{
Self-Measured Blood Pressure Monitoring: Program Planning, Implementation, and Lessons Learned From 5 Federally Qualified Health Centers in Hawai'i
}

\author{
David A. Stupplebeen, $\mathrm{PhD}^{1}$; Catherine M. Pirkle, $\mathrm{PhD}^{1}$; Tetine L. Sentell, $\mathrm{PhD}^{1}$; Blythe M. I. Nett, $\mathrm{MPH}^{2}$; \\ Lindsey S. K. Ilagan, $\mathrm{MS}^{2}$; Bryan Juan, MPH${ }^{3}$; Jared Medeiros, APRN ${ }^{4}$; L. Brooke Keliikoa, DrPH ${ }^{1}$
}

\begin{abstract}
Accessible Version: www.cdc.gov/pcd/issues/2020/19_0348.htm
Suggested citation for this article: Stupplebeen DA, Pirkle CM, Sentell TL, Nett BMI, Ilagan LSK, Juan B, et al. Self-Measured Blood Pressure Monitoring: Program Planning, Implementation, and Lessons Learned From 5 Federally Qualified Health Centers in Hawai'i. Prev Chronic Dis 2020;17:190348. DOI: https:// doi.org/10.5888/pcd17.190348.
\end{abstract}

\section{PEER REVIEWED}

\section{Summary}

What is already known on this topic?

Self-measured blood pressure monitoring programs (BPMPs) are effective in helping people with hypertension control their blood pressure.

What is added by this report?

This article explores the experiences of 5 Hawai'i-based Federally Qualified Health Centers (FQHCs) in implementing self-measured BPMPs. Because no nationally recognized self-measured BPMP curriculum existed at the time of this evaluation, the purpose of this article was to understand how FQHCs designed and implemented self-measured BPMPs in practice.

What are the implications for public health practice?

Policy makers, funding organizations, and intervention designers can draw on these experiences to make improvements to self-measured BPMPs in terms of support and toward the development of a standardized intervention curriculum.

\section{Abstract}

Self-measured blood pressure monitoring programs (BPMPs) are effective at controlling hypertension. We examined implementation of self-measured BPMPs at 5 Hawai'i-based Federally Qualified Health Centers (FQHCs). In a process evaluation of these programs, we found that FQHCs developed protocols for selfmeasured BPMP recruitment and enrollment and provided addi- tional supports to account for their patients' psychosocial needs to achieve blood pressure control, such as lifestyle change education and opportunities through referrals either to on-site or other programs (eg, on-site gym, tobacco cessation program). Common barriers across sites included insufficient material support for blood pressure monitors and data collection; funding, which affects program sustainability; and the lack of an "off-the-shelf" selfmeasured BPMP intervention. Policy makers and funding organizations should address these issues related to self-measured BPMPs to ensure implementation success.

\section{Background}

Self-measured blood pressure monitoring programs (BPMPs) are interventions for patients to track their blood pressure at home or in other nonclinical settings. They are used to diagnose high blood pressure, improve blood pressure control, and reduce the risk of related conditions, including heart disease, heart attacks, and stroke (1). Compared with usual care, self-measured BPMPs can substantially decrease blood pressure versus usual care, especially when combined with additional support (2), including patient counseling (eg, medication management, lifestyle change), education on blood pressure management, or access to electronic monitoring tools (3). Program delivery can encompass team-based care and include telemonitoring with support from pharmacists or registered nurses $(4,5)$. Implementing self-measured BPMPs in team-based care settings with other medical team members, such as community health workers (CHWs) (6), who work together with patients to achieve controlled blood pressure, is cost-effective (7).

\section{Purpose and Objectives}

In 2014, the Centers for Disease Control and Prevention (CDC) awarded funds to the Hawai'i Department of Health (HDOH), 
Hawai'i Primary Care Association (HPCA), and 9 Federally Qualified Health Centers (FQHCs) to increase use of self-measured BPMPs with clinical support (8). In 2015, Hawai'i FQHCs served more than 150,000 patients, $42.8 \%$ of whom were Native Hawaiian or other Pacific Islander (NHOPI) (9). More than three-quarters of patients had incomes below the federal poverty level in 2013 (10). Although 17,883 Hawai'i FQHC patients had hypertension in 2015 , only $64 \%$ had achieved blood pressure control (9). NHOPIs face socioeconomic barriers to hypertension management (11) similar to other populations who use FQHC services (12). At the start of the grant, there was no CDC-approved standardized curriculum for self-measured BPMPs; thus, FQHCs developed their own protocols and programs as part of their grant deliverables. In this article, we describe the self-measured BPMP components at 5 Hawai'i-based FQHCs during the grant period to highlight barriers and facilitators to program implementation.

\section{Evaluation Methods}

Evaluators from the University of Hawai' $i$ at Mānoa were contracted to provide a process evaluation that qualitatively assessed common self-measured BPMP components and that assessed barriers and facilitators at sites implementing the program. HPCA identified 5 FQHCs with self-measured BPMPs at varying levels of maturity; these FQHCs represented different practice settings (rural or urban) and patient population sizes (small or large). Health centers selected staff familiar with their self-measured BPMPs to participate in semi-structured video or telephone interviews, conducted in June and July 2018. Nine providers participated (Table 1), and all interviewees provided written consent. Evaluators asked how self-measured BPMP participants were identified, recruited, and enrolled; how programs were implemented; how patients were monitored; and about program barriers and facilitators. Four calls were recorded and transcribed; contemporaneous notes were taken during the fifth call. Transcripts and notes were qualitatively coded in Nvivo 11 (QSR International) and the primary evaluator (D.S.) deductively grouped codes into themes to mirror a typical programmatic logic model (ie, inputs, activities, outputs, and short-/long-term outcomes; see the CDC State Heart Disease and Stroke Prevention Program Evaluation Guide at www.cdc.gov/dhdsp/docs/logic_model.pdf). This evaluation was approved by the University of Hawai' $i$ at Mānoa institutional review board.

\section{Results}

Across the $5 \mathrm{FQHCs}$, the main program goals were to confirm a hypertension diagnosis and control blood pressure among those with diagnosed hypertension. The primary ways programs sought to achieve blood pressure control were through blood pressure monitoring and lifestyle change programs. We present the themes that emerged from interviews.

\section{Programmatic inputs and components}

\section{Inputs}

Self-measured BPMP programs started at various times. One site started in September 2016 and 3 sites started in October 2016. The remaining site had an existing self-measured BPMP that started before the grant in 2015, and it used grant funds to maximize its community care model with $\mathrm{CHWs}$. In addition to hiring support staff at all 5 centers, grant funds were used for additional program supplies (eg, log books). Interviewees said staff, existing program curricula related to blood pressure management, and patientcentered practices were important program inputs. All 5 FQHCs engaged CHWs or health educators in self-measured BPMPs, together with pharmacists, nurses, care coordinators, patient navigators, medical assistants, social workers, and/or nutritionists. The American Heart Association donated monitors, which facilitated the creation of a monitor loan program for patients who could not afford to purchase them, and provided educational materials. Other existing patient educational materials used by FQHCs included resources from $\mathrm{HDOH}$, a culturally tailored intervention called Ola Hou (hula for hypertension), and the National Diabetes Prevention Program (NDPP). Patient-centered practices, like working with patients to develop individual goals for controlling blood pressure, were important. One provider said, "Shared decisionmaking is, I think, progressively getting more incorporated into the management of the team as well as the providers."

\section{Program eligibility}

All FQHCs enrolled current patients with hypertension, although 3 sites also used their self-measured BPMPs to formally diagnose hypertension. FQHCs mainly used a systolic/diastolic threshold of 140/90 $\mathrm{mm} \mathrm{Hg}$ to determine eligibility, and 1 center also used 150/90 mm $\mathrm{Hg}$ for its patients who were older than 60 .

\section{Participant recruitment}

All FQHCs developed workflows for recruitment, which included internal bidirectional referral systems and electronic health record (EHR) algorithms to identify patients with undiagnosed hypertension. Participants were also recruited via existing programs at FQHCs, such as NDPP classes (Table 1). One site recruited participants through community wellness fairs and screening events; nonpatients were asked to become patients at the FQHC, at which time primary care providers (PCPs) formally referred these patients to the self-measured BPMP. PCPs at other FQHCs also made referrals directly to self-measured BPMP staff; however,

\footnotetext{
The opinions expressed by authors contributing to this journal do not necessarily reflect the opinions of the U.S. Department of Health and Human Services, the Public Health Service, the Centers for Disease Control and Prevention, or the authors' affiliated institutions.
} 
some program staff mentioned having to remind PCPs through meetings or other means that self-measured BPMP was an available resource.

\section{Program intake and delivery}

FQHCs used many of the same intake and enrollment procedures. Potential participants complete readiness assessments and program introductions with their PCP or self-measured BPMP staff assigned through the EHR. The level of patient assessment differed by site. One site asked permission of potential patients to schedule a time to explain the process. Another site conducted 3 different patient assessments because many of their clients had other underlying psychosocial issues, such as houselessness or mental illness: "We've had times ... where [the patients] come in, and then they don't really know what they're here for. Then they don't want to do it." After assessment, patients who were willing and able to participate were formally enrolled in the program.

At 4 FQHCs, patients signed a rental agreement for a loaner blood pressure monitor. A fifth $\mathrm{FQHC}$ provided reduced-price, Bluetooth-enabled monitors for purchase, so data could be transferred from the monitor directly into the clinic's health information system. This clinic's advanced practice registered nurse said, "We talk with the patient about the cost of the monitor being $\$ 35$ and that it's theirs. They can use it as much as they want, even that they could have 2 people use it in their household." Enrollment and setup sites included both the FQHC and patient homes. Clinics encouraged participants to take their blood pressure twice per day, although some patients only measured once per day. For sites with loaned monitors, self-measured BPMPs were conducted for 3 to 6 months; the FQHC that sold monitors had no end date for its program. Staff at all sites trained patients on the use and proper placement of the monitor cuff, proper posture during a blood pressure reading, and how to record the reading. Patients often logged their blood pressure readings by hand, and these data were then collected by staff either in the office or at participants' homes. Self-measured BPMP staff manually calculated average blood pressure and then entered the data into the EHR. Bluetoothenabled monitors used at 1 site allowed all blood pressure readings of patients to be digitally stored and electronically collected by the site's staff. PCPs and self-measured BPMP staff used the data to confirm hypertension or titrate medication as appropriate.

\section{Hypertension education and lifestyle change}

All 5 FQHCs included additional blood pressure education or lifestyle change components as part of their self-measured BPMPs. All sites provided diet-related education, including menu planning, food preparation demonstrations, referrals to nutritionists, or dietary information. Goal setting and motivational interviewing were also used by FQHCs to address barriers to lifestyle change and blood pressure monitoring. One site used its behavioral health team to address issues that affect patients' weight and hypertension:

\begin{abstract}
"We will utilize [behavioral health specialists] to meet with patients to discuss goals of wanting to lose some weight and some motivational cognitive behavioral therapy ... to help with some patients with multiple chronic diseases. These patients sometimes also have some behavioral health issues that we need to address as well."
\end{abstract}

Sites also reported adding in physical activity supports, including hula classes, group bicycle rides, and using on-site gyms or wellness programs. Some sites took advantage of existing on-site programs including NDPP classes, Ola Hou, tobacco cessation, or referrals to dietitians.

\section{Barriers and facilitators to implementing self- measured BPMPs}

Various barriers to implementing self-measured BPMPs and how sites overcame them were discussed (Table 2). Technologic limitations and availability of monitors were partially overcome by use of donated monitors from the local chapter of the American Heart Association. Patient-related barriers, especially houselessness or mental illness, potentially limited participation in programs; some clinics lost contact with these participants. One staff member said, "At the beginning, we were giving out the monitors at the first appointment. That caused us to lose a lot of monitors, because people wouldn't come back." Sites initiated readiness assessments and rental agreements to help with these issues.

Program reach was stymied by a lack of provider referrals because of competing demands. One staff member said, "I hear it from other programs, too, that they don't get a lot of referrals in general. From what I hear, it's that [PCPs] have so many other things to do in a visit or whatnot, that this may not be their top priority type of thing." Staff at 2 different sites mentioned that turnover of PCPs and self-measured BPMPs staff affected capacity, with one saying, "Staff turnover in the recent past has led to backlog of referrals ... the maximum capacity is 2 patients per day." One site had started their program using an in-house pharmacist; however, the main funding for that position ended, and program operation was moved to other health education staff. Turnover, although challenging, was partially addressed through presentations of self-measured BPMPs to new PCPs.

In addition to other systemic barriers, interviewees frequently mentioned the lack of an "out-of-the-box" self-measured BPMP curriculum, which led program staff to combine materials from a variety of sources. Systemic facilitators included funding to initi-

The opinions expressed by authors contributing to this journal do not necessarily reflect the opinions of the U.S. Department of Health and Human Services, the Public Health Service, the Centers for Disease Control and Prevention, or the authors' affiliated institutions. 
ate self-measured BPMPs, technical assistance and shared capacity-building with other implementing sites, and availability of existing educational materials. Another barrier mentioned was the lack of an agreed-upon hypertension diagnosis standard $(2,15)$ among PCPs. One clinic received additional capacity-building assistance on self-measured BPMPs from clinicians who had previously developed a self-measured BPMP (4). Patient word-ofmouth about the program helped spread information about hypertension and encouraged others to participate. Lastly, the patientcentered and team-based care models used by FQHCs and integration of self-measured BPMPs into clinic workflows were important facilitators, which have been effective in other studies (5).

\section{Implications for Public Health Practice}

This process evaluation identified several lessons learned and potential recommendations for policy makers and funding organizations. Foremost, recruitment, scaling, and sustainability were limited by the lack of material supports (eg, monitors) for program implementation, and staff turnover was a major barrier. Funding for other self-measured BPMP positions, like CHWs, is often grant-based, which can lead to burnout and contribute to turnover (16). Four FQHCs limited their program duration because they loaned monitors to patients who could not afford them, while the fifth site performed continuous monitoring, because patients purchased the monitors and because hypertension is a chronic condition. Manual calculation and entry of blood pressure readings into EHRs was a time-consuming process. Data management difficulties hindered further evaluation of the effectiveness of selfmeasured BPMPs and highlighted the importance of improving the ease and quality of data collection for both patients and providers.

Funding organizations should address the lack of material resources, challenges to remote data collection and monitoring, program reimbursement, and the need for cost-effective health information technology to improve self-measured BPMP uptake and support program sustainability, especially for organizations with populations like those served by FQHCs. In 2018, Hawai'i FQHCs served 157,097 patients, of whom 22,509 had hypertension; of those, $39 \%$ had yet to achieve blood pressure control (17), demonstrating the ongoing need for self-measured BPMPs. Second, patients' needs or more urgent health matters interfered with participation in self-measured BPMPs; this was compounded by the lack of an "off-the-shelf" self-measured BPMP curriculum. To address this, sites first assessed patients individually for participation readiness to ensure patients were able to succeed. Second, sites compiled materials from existing programs on dietary and behavior modifications to educate participants on lifestyle changes to manage blood pressure. Then sites provided instrumental supports, such as opportunities for exercise or leveraging existing lifestylechange programs. Lastly, FQHCs' team-based care model involved multiple layers of staff to help manage self-measured BPMPs participants and their needs, such as CHWs going to participant homes for monitor setup and data gathering. We were unable to assess whether these social supports or patients' own motivation were contributors to self-measured BPMP enrollment. We were also not able to assess whether differences in manual or Bluetooth-connected monitors, the primary instrumental support provided in these programs, affected compliance and program adherence by participants. Future research should examine these factors. Funders and policy makers should convene sites to provide input on their self-measured BPMP implementation experiences to help develop an off-the-shelf program based on lessons learned.

Five Hawai' $i$-based FQHCs implemented self-measured BPMPs that strategically addressed patients' psychosocial and health needs. Systemic barriers hindered the sustainability of selfmeasured BPMPs at some sites and access to data, which hindered an outcome evaluation of these efforts. Policy makers should consider developing off-the-shelf self-measured BPMPs and provide material support to implementation sites through blood pressure monitor reimbursement and further financial support to maintain clinic staff.

\section{Acknowledgments}

This study was supported by CDC State and Local Public Health Actions to Prevent Obesity, Diabetes, and Heart Disease and Stroke Grant (no. DP14-1422 1U58DP005502). Its contents are solely the responsibility of the authors and do not necessarily represent the official views of the CDC, the Hawaii Department of Health, or its grant partners. The authors thank staff from the participating FQHCs for taking the time to share their perspectives and reflections for this evaluation study. No copyrighted tools or instruments were used in this evaluation.

\section{Author Information}

Corresponding Author: David A. Stupplebeen, PhD, Office of Public Health Studies, University of Hawai' $i$ at Mānoa, 1960 EastWest Road, Biomed D-210, Honolulu, HI 96822. Telephone: 808956-5505. Email: dstupp@hawaii.edu.

Author Affiliations: ${ }^{1}$ Healthy Hawai'i Initiative Evaluation Team, Office of Public Health Studies, University of Hawai'i at Mānoa, Honolulu, Hawaii. ${ }^{2}$ Chronic Disease Prevention and Health Promotion Division, Hawai'i State Department of Health, Kapolei,

The opinions expressed by authors contributing to this journal do not necessarily reflect the opinions of the U.S. Department of Health and Human Services, the Public Health Service, the Centers for Disease Control and Prevention, or the authors' affiliated institutions. 
Hawaii. ${ }^{3}$ Hawai'i Primary Care Association, Honolulu, Hawaii. ${ }^{4}$ Lāna'i Community Health Center, Lāna'i City, Hawaii.

\section{References}

1. Centers for Disease Control and Prevention. Self-measured blood pressure monitoring: action steps for clinicians. Atlanta (GA): Centers for Disease Control and Prevention, US Department of Health and Human Services; 2014. https:// millionhearts.hhs.gov/files/MH_SMBP_Clinicians.pdf. Accessed July 12, 2018.

2. Whelton PK, Carey RM, Aronow WS, Casey DE Jr, Collins KJ, Dennison Himmelfarb C, et al. 2017 ACC/AHA/AAPA/ ABC/ACPM/AGS/APhA/ASH/ASPC/NMA/PCNA guideline for the prevention, detection, evaluation, and management of high blood pressure in adults: a report of the American College of Cardiology/American Heart Association Task Force on Clinical Practice Guidelines. Hypertension 2018; 71(6):e13-115.

3. Task Force on Community Preventive Services. Self-measured blood pressure monitoring improves outcomes: recommendation of the Community Preventive Services Task Force. Am J Prev Med 2017;53(3):e115-8.

4. Margolis KL, Asche SE, Bergdall AR, Dehmer SP, Groen SE, Kadrmas HM, et al. Effect of home blood pressure telemonitoring and pharmacist management on blood pressure control: a cluster randomized clinical trial. JAMA 2013; 310(1):46-56.

5. Kravetz JD, Walsh RF. Team-based hypertension management to improve blood pressure control. J Prim Care Community Health 2016;7(4):272-5.

6. Brownstein JN, Chowdhury FM, Norris SL, Horsley T, Jack L Jr, Zhang X, et al. Effectiveness of community health workers in the care of people with hypertension. Am J Prev Med 2007; 32(5):435-47.

7. Jacob V, Chattopadhyay SK, Proia KK, Hopkins DP, Reynolds J, Thota AB, et al.; Community Preventive Services Task Force. Economics of self-measured blood pressure monitoring: a Community Guide systematic review. Am J Prev Med 2017; 53(3):e105-13.

8. Rutledge GE, Lane K, Merlo C, Elmi J. Coordinated approaches to strengthen state and local public health actions to prevent obesity, diabetes, and heart disease and stroke. Prev Chronic Dis 2018;15:E14.

9. Health Resources and Services Administration. 2017Hawaii Health Center data. https://bphc.hrsa.gov/uds/ datacenter.aspx?year=2017\&state=HI. Accessed May 3, 2019.
10. Hawai'i Department of Health, Family Health Services Division. State of Hawai'i Department of Health primary care needs assessment data book; 2016. http://health.hawaii.gov/ about/files/2013/06/pcna2016databook-c.pdf. Accessed November 30, 2018.

11. Kaholokula JK, Look M, Mabellos T, Zhang G, de Silva M, Yoshimura S, et al. Cultural dance program improves hypertension management for Native Hawaiians and Pacific Islanders: a pilot randomized trial. J Racial Ethn Health Disparities 2017;4(1):35-46.

12. Russell BE, Gurrola E, Ndumele CD, Landon BE, O’Malley JA, Keegan T, et al.; Community Health and Academic Medicine Partnership Project. Perspectives of non-Hispanic black and Latino patients in Boston's urban community health centers on their experiences with diabetes and hypertension. J Gen Intern Med 2010;25(6):504-9.

13. US Department of Health and Human Services, Health Resource and Services Administration. 2018Health center program awardee data. https://bphc.hrsa.gov/uds/ datacenter.aspx? $\mathrm{q}=\mathrm{d} \&$ year $=2018 \&$ state $=$ HI\#glist. Accessed March 24, 2020.

14. National Heart, Lung, and Blood Institute. DASH Diet. https:// www.nhlbi.nih.gov/health-topics/dash-eating-plan. Accessed March 24, 2020.

15. Qaseem A, Wilt TJ, Rich R, Humphrey LL, Frost J, Forciea MA; Clinical Guidelines Committee of the American College of Physicians and the Commission on Health of the Public and Science of the American Academy of Family Physicians. Pharmacologic treatment of hypertension in adults aged 60 years or older to higher versus lower blood pressure targets: a clinical practice guideline from the American College of Physicians and the American Academy of Family Physicians. Ann Intern Med 2017;166(6):430-7.

16. Stupplebeen DA, Sentell TL, Pirkle CM, Juan B, BarnettSherrill AT, Humphry JW, et al. Community health workers in action: community-clinical linkages for diabetes prevention and hypertension management at 3 community health centers. Hawaii J Med Public Health 2019;78(6Suppl 1):15-22.

17. Bureau of Primary Health Care. Health Resources and Services Administration. 2018Hawaii Health Center Data - Hawaii Program Data. https://bphc.hrsa.gov/uds/ datacenter.aspx? year $=2018 \&$ state $=$ HI. 2019. Accessed September 20, 2019.

The opinions expressed by authors contributing to this journal do not necessarily reflect the opinions of the U.S. Department of Health and Human Services, the Public Health Service, the Centers for Disease Control and Prevention, or the authors' affiliated institutions. 


\section{Tables}

Table 1. Workflow of Self-Measured Blood Pressure Monitoring Programs at 5 Hawai'i Community Health Centers

\begin{tabular}{|c|c|c|c|c|c|}
\hline \multirow[b]{2}{*}{$\begin{array}{l}\text { Health Center Number/ } \\
\text { Location/Size }\end{array}$} & \multirow[b]{2}{*}{ Interviewees } & \multirow{2}{*}{$\begin{array}{l}\% \text { of Patients } \\
\text { With } \\
\text { Hypertension } \\
(2018)^{\mathrm{a}}\end{array}$} & \multicolumn{3}{|c|}{ Activities } \\
\hline & & & Recruitment & $\begin{array}{l}\text { Intake, Program Delivery, and } \\
\text { Follow-Up }\end{array}$ & $\begin{array}{l}\text { Hypertension Education and Lifestyle } \\
\text { Change }\end{array}$ \\
\hline 1. Rural/large & $2 \mathrm{CHWs}$ & 27.8 & $\begin{array}{l}\text { - Recruitment: } \\
\text { DPP, EHR } \\
\text { - Referral: } \\
\text { physician } \\
\text { - Outreach: } \\
\text { community, FQHC } \\
\text { physicians }\end{array}$ & $\begin{array}{l}\text { - Intake: readiness assessment and } \\
\text { introduction } \\
\text { - Enrollment location: office or home } \\
\text { - Measurement training: office or in } \\
\text { home } \\
\text { - Monitor set-up: in home } \\
\text { - Program length: target, } 3-6 \text { months } \\
\text { - Log collection: office or home } \\
\text { - Calculation: manual, entered into } \\
\text { EHR for physician }\end{array}$ & $\begin{array}{l}\text { - Counseling and goal setting } \\
\text { - Physical activity: planning, off-site group } \\
\text { activities (eg, hula, bicycle rides) } \\
\text { - Diet: healthy eating } \\
\text { - Referrals: DPP, care management }\end{array}$ \\
\hline 2. Urban/large & $\begin{array}{l}\text { Program } \\
\text { coordinator }\end{array}$ & 16.0 & $\begin{array}{l}\text { - Recruitment: DPP } \\
\text { - Referral: } \\
\text { physician }\end{array}$ & $\begin{array}{l}\text { - Intake: readiness assessment, } \\
\text { introduction, hypertension education } \\
\text { before enrollment ( } 3 \text { sessions) } \\
\text { - Enrollment location: office } \\
\text { - Measurement training: office } \\
\text { - Monitor set-up: office } \\
\text { - Program length: target, } 5 \text { months } \\
\text { - Log collection: office } \\
\text { - Calculation: manual }\end{array}$ & $\begin{array}{l}\text { - Physical activity: planning, on-site } \\
\text { trainer/gym } \\
\text { - Diet: DASH }{ }^{\text {b }} \text { education } \\
\text { - Referrals: dietician, tobacco cessation }\end{array}$ \\
\hline 3. Rural/large & $\begin{array}{l}\text { Pharmacist, } 2 \\
\text { CHWs }\end{array}$ & 25.7 & $\begin{array}{l}\text { - Recruitment: EHR } \\
\text { - Referral: } \\
\text { physician }\end{array}$ & $\begin{array}{l}\text { - Intake: readiness assessment and } \\
\text { introduction } \\
\text { - Enrollment location: pharmacy } \\
\text { - Measurement training: office } \\
\text { - Monitor set-up: office } \\
\text { - Program length: } 3 \text { months } \\
\text { - Log collection: office once per } \\
\text { month } \\
\text { - Calculation: manual, entered into } \\
\text { EHR for physician }\end{array}$ & $\begin{array}{l}\text { - Physical activity: planning, on-site gym } \\
\text { - Diet: nutritionist/dietitian referral } \\
\text { - Incentive program: diet/physical } \\
\text { activity-related incentives } \\
\text { - Referrals: tobacco use cessation, sleep } \\
\text { studies }\end{array}$ \\
\hline 4. Rural/small & APRN, physician & 20.9 & $\begin{array}{l}\text { - Recruitment: EHR } \\
\text { - Referral: } \\
\text { physician }\end{array}$ & $\begin{array}{l}\text { - Intake: readiness assessment and } \\
\text { introduction } \\
\text { - Enrollment location: office or home } \\
\text { - Measurement training: office or } \\
\text { home } \\
\text { - Monitor set-up: office or home } \\
\text { - Program length: unlimited } \\
\text { - Log collection: at home or in office, } \\
\text { transferred by tablet to health } \\
\text { information system } \\
\text { - Calculation: electronic, health } \\
\text { information system }\end{array}$ & $\begin{array}{l}\text { - Counseling and goal setting } \\
\text { - Physical activity: planning, on-site } \\
\text { wellness program } \\
\text { - Diet: planning, PILI 'Ohana (existing } \\
\text { culturally adapted diabetes curriculum for } \\
\text { Native Hawaiians and other Pacific } \\
\text { Islanders) } \\
\end{array}$ \\
\hline 5. Urban/large & $\begin{array}{l}\text { Program } \\
\text { coordinator }\end{array}$ & 38.7 & $\begin{array}{l}\text { - Recruitment: EHR } \\
\text { - Referral: } \\
\text { physician } \\
\text { - Outreach: } \\
\text { patients and FQHC } \\
\text { physicians }\end{array}$ & $\begin{array}{l}\text { - Intake: readiness assessment and } \\
\text { introduction } \\
\text { - Enrollment location: office } \\
\text { - Measurement training: office or } \\
\text { home } \\
\text { - Monitor set-up: office or home } \\
\text { - Program length: } 3 \text { months } \\
\text { - Log collection: at home or in office } \\
\text { - Calculation: manual, entered into } \\
\text { EHR for physician }\end{array}$ & $\begin{array}{l}\text { - Physical activity: on-site group activities } \\
\text { (eg, hula) } \\
\text { - Diet: food demonstrations } \\
\text { - Ola Hou lessons (culturally adapted } \\
\text { existing self-measured blood pressure } \\
\text { monitoring program curriculum) } \\
\text { - Referrals: medication payment } \\
\text { assistance }\end{array}$ \\
\hline
\end{tabular}

Abbreviations: APRN, advanced practice registered nurse; CHW, community health worker; DASH, Dietary Approaches to Stop Hypertension; DPP, National Diabetes Prevention Program classes; EHR, electronic health record; FQHC, federally qualified health center.

a small health center had $<10,000$ clients on average during 2016-2018; large centers had $\geq 10,000$ on average for the same period. Source: US Department of Health and Human Services, Health Resources and Services Administration (13).

${ }^{\mathrm{b}}$ Source: National Heart, Lung, and Blood Institute (14).

The opinions expressed by authors contributing to this journal do not necessarily reflect the opinions of the U.S. Department of Health and Human Services, the Public Health Service, the Centers for Disease Control and Prevention, or the authors' affiliated institutions. 
Table 2. Barriers and Facilitators to Implementing Self-Measured Blood Pressure Monitoring Programs (BPMPs) at 5 Hawai'i-based Federally Qualified Health Centers

\begin{tabular}{|c|c|}
\hline Category & Action \\
\hline \multicolumn{2}{|l|}{ Barrier } \\
\hline \multicolumn{2}{|l|}{ Availability and limitations of blood pressure monitors } \\
\hline $\begin{array}{l}\text { - Monitors costly for patients, clinics } \\
\text { - Older monitors not Bluetooth-enabled, led to hand calculating blood pressure averages, } \\
\text { which was time consuming }\end{array}$ & Used donated monitors, create monitor loan program for patients \\
\hline \multicolumn{2}{|l|}{ Patient-related issues } \\
\hline $\begin{array}{l}\text { Disabilities, family, finances, houselessness, immigration status, fear of hypertension or } \\
\text { worsening of condition, and transportation }\end{array}$ & $\begin{array}{l}\text { - Staff implemented readiness assessments to identify patients } \\
\text { willing and able to participate } \\
\text { - Some sites implemented pre-enrollment education before } \\
\text { distribution of monitors } \\
\text { - Institute monitor loan agreements } \\
\text { - Assist patients in their homes }\end{array}$ \\
\hline \multicolumn{2}{|l|}{ Staffing challenges } \\
\hline Provider turnover and other patient needs led to a lack of referrals & $\begin{array}{l}\text { Self-monitored BPMP staff had to train refresh physicians to remind } \\
\text { them of the service }\end{array}$ \\
\hline \multicolumn{2}{|l|}{ Systemic challenges } \\
\hline $\begin{array}{l}\text { - No single "out-of-the-box" self-measured BPMP program available } \\
\text { - Lack of integrated data management between monitors and electronic health records } \\
\text { - Uniform data system reporting } \\
\text { - Disagreement about hypertension diagnostic cutoffs led to delayed referrals at one center } \\
\text { - Funding and reimbursement for program sustainability }\end{array}$ & $\begin{array}{l}\text { - Staff constructed programs from existing materials, } \\
\text { recommendations } \\
\text { - One site used Bluetooth-enabled monitors to transfer data to } \\
\text { electronic health record }\end{array}$ \\
\hline \multicolumn{2}{|l|}{ Facilitator } \\
\hline \multicolumn{2}{|l|}{ Systemic } \\
\hline Grant funding & $\begin{array}{l}\text { Allowed sites to hire staff for self-measured BPMPs, access technical } \\
\text { assistance to build programs }\end{array}$ \\
\hline Shared technical assistance & Sites helped each other and shared tips and ideas \\
\hline Existing resources & $\begin{array}{l}\text { American Heart Association resources, other educational programs } \\
\text { materials, capacity-building assistance }\end{array}$ \\
\hline \multicolumn{2}{|l|}{ Patient-related } \\
\hline Program word-of-mouth & $\begin{array}{l}\text { Patients let others know about the program and availability of blood } \\
\text { pressure monitors }\end{array}$ \\
\hline Hypertension education & $\begin{array}{l}\text { Patients helped diffuse information about hypertension to families/ } \\
\text { friends }\end{array}$ \\
\hline \multicolumn{2}{|l|}{ Clinical practice-related } \\
\hline Patient-centered/team-based approaches & $\begin{array}{l}\text { Clinics used a variety of staff, including clinicians, pharmacists, and } \\
\text { CHWs, who employed patient-centered approaches (eg, lifestyle } \\
\text { change, home visits) }\end{array}$ \\
\hline Integrating self-measured BPMPs into clinic practice & $\begin{array}{l}\text { Integration of self-measured BPMPs into clinical workflows, including } \\
\text { into the electronic medical record for referral and entering blood } \\
\text { pressure readings }\end{array}$ \\
\hline
\end{tabular}

Abbreviations: CHWs, community health workers; BPMPs, blood-pressure monitoring programs. 